\title{
A escravidão em uma perspectiva comparativa: Caçapava do Sul (RS, Brasil) e Brazoria (Texas) - primeira metade do século XIX
}

\author{
Slavery in a comparative perspective: Caçapava do Sul (RS, Brazil) and Brazoria (Texas)- \\ first half of the nineteenth century
}

Esclavitud en una perspectiva comparativa: Caçapava do Sul (RS, Brasil) y Brazoria (Texas) primera mitad del siglo XIX

Marcelo Santos Matheus ${ }^{*}$

Andrédo Nascimento Corrêa*

\section{Resumo}

Na década de 1940, com a publicação de Slave and Citizen (1947), de F. Tannenbaum, inaugurou-se um novo ramo historiográfico: a comparação entre os sistemas escravistas montados nas Américas. É neste contexto historiográfico que o presente estudo se insere. Nele, comparamos as características das escravarias de duas localidades, Caçapava do Sul, na província do Rio Grande do Sul (Brasil), e Brazoria, na então República do Texas. Para tanto, as fontes utilizadas foram uma lista de fogos (de 1830, para Caçapava do Sul) e um levantamento de propriedades e bens (de 1840, para Brazoria). De antemão, é possível afirmar que, apesar de o número de fogos e a quantidade de escravos em Caçapava do Sul e Bra- zoria serem parecidos, na primeira, a posse escrava estava amplamente disseminada pelo tecido social, ao contrário de Brazoria, onde apenas cerca de 1/3 dos fogos eram de escravistas. Da mesma forma, em Caçapava do Sul predominavam as pequenas e médias escravarias, que concentravam boa parte dos cativos, diferentemente de Brazoria, onde os grandes plantéis concentravam a absoluta maioria dos cativos.

Palavras-chave: Comparação. Escravidão. Estrutura de posse.

Doutor em História Social pela Universidade Federal do Rio de Janeiro. E-mail: msmportugues@ hotmail.com

** Doutor em História pela Universidade do Vale do Rio dos Sinos. E-mail: andrecorreacp@gmail.com

Recebido em: 20/10/2017 - Aprovado em: 12/12/2017 http://dx.doi.org/10.5335/hdtv.18n.2.8074 


\section{Introdução}

Como destacaram há muito tempo Eugene Genovese e Laura Foner, a obra Slave and Citizen, de Frank Tannenbeum, publicada pela primeira vez em meados da década de 1940, inaugurou um ramo historiográfico que tem na comparação entre diferentes sistemas escravistas - no caso de Slave and Citizen, entre a escravidão nos países de colonização inglesa e nos de colonização ibérica - a linha mestra de sua narrativa (TANNENBAUM, 1947; FONER; GENOVESE, 1969, p. VII). Apesar do ineditismo do livro, por décadas, os estudos comparativos não ganharam fôlego. ${ }^{1}$

No entanto, aproximadamente nos últimos trinta anos, uma série de pesquisas passou a ser produzida com diferentes enfoques e comparando diferentes regiões das Américas. ${ }^{2}$ Ainda assim, em ensaio recente (2012), Herbert Klein observou que, nos últimos anos, os pesquisadores têm "negligenciado, nas discussões recentes sobre a diáspora africana nas Américas, [...] a comparação das diferenças e semelhanças entre os regimes escravistas" (2012, p. 95-96). É neste contexto que o presente estudo se insere, mas com alguns objetivos específicos.

Nele, comparamos algumas características das escravarias de duas localidades Caçapava do Sul, que se localizava na região central da província do Rio Grande do Sul (RS), no extremo sul do Império do Brasil, e Brazoria, um condado da então República do Texas, localizado praticamente às margens do Golfo do México. Para tanto, valemo-nos de duas fontes distintas, mas que, ao nosso ver, servem para os propósitos estabelecidos neste estudo.
Para Caçapava do Sul, exploramos uma fonte rara para a região: a Lista de fogos (INSTITUTO HISTÓRICO E GEOGRÁFICO DO RIO GRANDE DO SUL, 1830) produzida no ano de 1830. Já, para Brazoria, utilizamos The 1840 Census of Republic of Texas (WHITE, 1966) que, na verdade, foi um levantamento de bens e propriedades, para que a nova república, endividada com a guerra pela independência contra o México, pudesse tributar os cidadãos.

Nesse sentido, em um primeiro momento, apresentamos rapidamente as regiões foco do estudo. Em seguida, passamos às comparações propriamente ditas, começando pela quantificação dos fogos com e sem escravos; na sequência, realizamos uma estrutura de posse escrava, para analisar qual a envergadura dos plantéis; por último, averiguamos a concentração de escravos entre as pequenas, médias e grandes escravarias. Para finalizar, propomos uma pequena reflexão a partir dos resultados encontrados, verificando em que sentido a escravidão, ou melhor, a disseminação da posse escrava, a estrutura dos plantéis e a concentração ou não de cativos se aproximavam ou se afastavam de uma localidade para outra e quanto esses aspectos nos informam sobre as semelhanças e diferenças da escravidão nas duas regiões analisadas.

\section{Nas fronteiras americanas: Caçapava do Sul (RS) e Brazoria (Texas)}

A ocupação do sul do Império do Brasil e do sudoeste do atual Estados Unidos da América (EUA), nas primeiras décadas do século XIX, estava inserida em uma expan- 
são migratória que tinha por objetivo a apropriação de recursos (terras, principalmente, e gado). Tanto os luso-brasileiros quanto os cidadãos dos EUA produziram correntes migratórias para regiões - algumas delas ocupadas por indígenas - que (ainda) não pertenciam às duas nações. Se, no Brasil, os luso-brasileiros conseguiram expandir a fronteira sul do império por meio de guerras, da apropriação de terras e de instalação de capelas, anexando os sete povos da margem oriental do Rio Uruguai, a oeste, e ocupando terras até o rio Quaraí, ao sul, conformando as fronteiras do atual estado do RS, o caso do Texas foi um pouco diferente (FARINATTI, 2010; ALADRÉN, 2012; MATHEUS, 2013).

Muitos americanos ${ }^{3}$ migraram para o estado de Coahuila e Texas por iniciativa do governo mexicano, preocupado em povoar a região. Apesar de, desde 1816, alguns colonos advindos dos EUA já fincassem raízes no Texas, o crescimento do processo migratório intensificou-se entre 1820 e 1821, quando Moses Austin negociou com as autoridades locais, em San Antonio, a legalização dos imigrantes americanos que se dirigissem para o Texas. Com a morte de Moses, seu filho, Stephen Austin, prosseguiu com o projeto de migração e colonização. Stephen elaborou uma proposta de distribuição das terras, em que cada chefe de família migrada receberia uma porção de terras, mais 50 acres por escravo que a família possuísse. Com o tempo, ele conseguiu que as autoridades aumentassem para 80 acres por escravo. Com o aceite em mãos, Stephen retornou aos EUA para recrutar colonos (MASSEY, 2000, p. 13; MACGHEE, 2000, p. 152; NEAL, 2001, p. 44). ${ }^{4}$
Contudo, em 1821, quando o México tornou-se independente, começaram os conflitos entre os americanos e as autoridades do governo mexicano, em razão de este querer extirpar a escravidão de seu território. Mesmo assim, a onda migratória de americanos continuou aumentando. Resumindo, de um processo que foi longo e complexo, as rusgas entre o governo mexicano e os colonos em torno da escravidão (indispensável na visão dos americanos) levaram estes a se revoltarem contra o governo e declararem guerra em outubro de 1835, conflito que resultou na independência da República do Texas (CAMPBELL, 1989).

O fenômeno mencionado (a migração de senhores, rumo à fronteira, com seus escravos) também aconteceu no RS. Nas duas regiões, esse processo de migração, a reprodução natural e a compra de escravos (tanto via tráfico atlântico - até 1850, no Brasil, e via tráfico ilegal, nos EUA -, quanto de outras províncias/estados) fizeram com que a população escrava no Texas e no RS crescesse ao longo do século (Tabela 1).

Tabela 1 - Comparação entre a população escrava no Texas no RS (anos selecionados)

\begin{tabular}{|c|c|c|}
\hline \multirow{2}{*}{ Ano } & \multicolumn{2}{|c|}{$\mathrm{N}^{0}$ de escravos } \\
\hline & RS & Texas \\
\hline $1814-1846$ & 20.611 & 30.505 \\
\hline $1858-1852$ & 71.911 & 68.584 \\
\hline $1862-1855$ & 77.416 & 105.186 \\
\hline $1873-1861$ & 83.370 & 169.166 \\
\hline
\end{tabular}

Fonte: Campbell (1989, p. 56) e Fundação de Economia e Estatística (1981, p. 77). 
Voltando às localidades foco do presente estudo, muito embora a ocupação da localidade de Caçapava do Sul date do final do século XVIII, apenas em 1800 foi erguida uma capela para que fossem atendidas as necessidades espirituais dos luso-brasileiros que se dirigiram para o local. Em 1831, Caçapava do Sul foi elevada à categoria de vila. Durante todo o século XIX, a principal atividade econômica da localidade foi a pecuária, embora a pequena agricultara fosse praticada (CORRÊA, 2013, p. 33-35).

Por sua vez, Brazoria foi uma das primeiras colônias fundadas por americanos, ainda no início da década de 1820, e, em razão de suas terras férteis, atraiu uma grande quantidade de colonos. Em 1832, o governo mexicano a instituiu distrito, e, em 1836, quando o Texas já havia conquistado a independência, tornou-se um dos primeiros condados (STROBEL, 1980). O que movia a economia da região eram as plantações de açúcar e algodão, apesar de a pecuária também ter certa importância (NEAL, 2001, p. 58; DEBOW, 1990). Essas cidades (para suas localizações, em meados de 1850, ver Figuras 1 e 2) servirão de lócus para as comparações a seguir.

\section{A escravidão em uma perspectiva comparativa}

Como já referido, nosso estudo explora duas fontes de natureza diversa, isto é, que foram produzidas com diferentes propósitos. Por isso, as fontes consultadas não são, no todo, homogêneas. Por exem- plo, na Lista de fogos de Caçapava do Sul (INSTITUTO HISTÓRICO E GEOGRÁFICO DO RIO GRANDE DO SUL, 1830), encontramos algumas informações que não constam na fonte utilizada para Brazoria, como os nomes dos escravos (e, logo, seu sexo), a existência ou não de agregados (e, da mesma forma, seus nomes), alguns qualitativos, como coronel, tenente e dona, ou mesmo a indicação de condição jurídica/social, como forro e índio; já, no The 1840 Census of Republic of Texas (WHITE, 1966), o único dado que não encontramos na Lista de fogos são alguns dos bens tributáveis, como a extensão das terras (e se os proprietários tinham o título ou a simples posse desses bens). ${ }^{5}$

Desse modo, aspectos interessantes, como a razão de sexo e as faixas etárias em diferentes tamanhos de plantéis, ficam impossibilitados de ser analisados. Essas diferenças, entretanto, não prejudicam os objetivos traçados. Antes de passarmos a eles, cumpre destacar que na Lista de fogos (INSTITUTO HISTÓRICO E GEOGRÁFICO DO RIO GRANDE DO SUL, 1830) foram arrolados 286 fogos - 238 (ou 83\%) chefiados por homens e 48 (ou $17 \%)$ chefiados por mulheres. Entre eles, 18 chefes foram designados pardo, índio, e, em um caso, forro. No The 1840 Census of Republic of Texas (WHITE, 1966), foram listados 309 fogos - por volta de $92 \%$ deles chefiados por homens e $8 \%$ por mulheres. Os quase $10 \%$ de chefes de fogos do sexo feminino chamam atenção, já que a lei determinava que todo "homem branco com mais de 21 anos" e proprietário de bens taxáveis devesse pagar o imposto. ${ }^{6} \mathrm{Na} \mathrm{Ta}-$ 
bela 2, é possível observar a distribuição dos fogos escravistas e não escravistas nas duas localidades:

Tabela 2 - Distribuição dos fogos escravistas e não escravista de Caçapava do Sul (1830) e Brazoria (1840)

\begin{tabular}{l|r|r|r|r|r}
\hline \multicolumn{1}{c|}{ Localidade } & \multicolumn{1}{c|}{$\begin{array}{c}\text { Com } \\
\text { escravos }\end{array}$} & \multicolumn{1}{c|}{$\%$} & $\begin{array}{c}\text { Sem } \\
\text { escravos }\end{array}$ & \multicolumn{1}{c}{$\%$} & Total \\
\hline Caçapavado Sul & 192 & 67 & 94 & 33 & 286 \\
Brazoria & 94 & 30,5 & 215 & 69,5 & 309 \\
\hline
\end{tabular}

Fonte: Instituto Histórico e Geográfico do Rio Grande do Sul (1830) e White (1966, p. 123).

Se o número de fogos das duas localidades (309 em Brazoria e 286 em Caçapava do Sul) e o total de escravos mencionados nas fontes (em Caçapava do Sul, 1.130 foram arrolados, enquanto, em Brazoria, o montante chegou a 1.212) são bastante parecidos, na análise dos fogos com e sem cativos reside uma das principais diferenças entre a escravidão em Caçapava do Sul e Brazoria, a partir das fontes analisadas neste estudo. Na primeira, nada menos do que 2 em cada 3 fogos eram de escravistas, enquanto que, em Brazoria, cerca de $1 / 3$ dos fogos eram de senhores de escravos.
No entanto, talvez essa grande diferença tenha que ser matizada. No censo de 1850, quando o Texas já havia sido anexado aos EUA, 160 (ou cerca de 54\%) dos 296 fogos de Brazoria eram de escravistas. ${ }^{7}$ Possivelmente a guerra pela independência e a incerteza (que, de resto, também existia, do ponto de vista dos luso-brasileiros, para muitas áreas limítrofes do RS na primeira metade do século XIX) se aquela região seria ou não incorporada novamente ao México, onde a escravidão havia sido extinta, respondem por parte dessa diferença. Assim, quando os conflitos cessaram, e o território foi incorporado aos EUA, aumentou a migração de colonos e colonos com escravos, elevando o número de fogos com cativos (CAMPBELL, 1989, p. 51).

Realizando uma média de escravos por fogo (e, claro, levando em conta apenas os fogos com cativos), temos que os 1.130 escravos, em Caçapava do Sul, representam quase 6 escravos em cada fogo; enquanto que, em Brazoria, os 1.212 cativos arrolados significam uma média de cerca de 13 escravos por fogo. Essa grande diferença - mais do dobro de escravos em média por fogo em Brazoria - tem relação, por óbvio, com os resultados encontrados para a estrutura de posse e também com a concentração de escravos, como mostra-se a seguir. 
Tabela 3 - Envergadura dos senhores escravos, Caçapava do Sul (1830) e Brazoria (1840)

\begin{tabular}{|c|c|c|c|c|c|c|c|c|c|}
\hline - & $\begin{array}{c}\text { Caçapava } \\
\text { do Sul }\end{array}$ & $\%$ & Brazoria & $\%$ & - & $\begin{array}{c}\text { Caçapava } \\
\text { do Sul }\end{array}$ & $\%$ & Brazoria & $\%$ \\
\hline Com 1 escravo & 40 & & 15 & & Com 22 escravos & 1 & \multirow{20}{*}{6} & 1 & \multirow{17}{*}{22,5} \\
\hline Com 2 escravos & 31 & & 12 & & Com 23 escravos & 1 & & - & \\
\hline Com 3 escravos & 17 & 56 & 10 & 44,5 & Com 24 escravos & 1 & & 2 & \\
\hline Com 4 escravos & 20 & & 5 & & Com 25 escravos & - & & 1 & \\
\hline Com 5 escravos & 13 & & 2 & & Com 27 escravos & 1 & & 3 & \\
\hline Com 6 escravos & 12 & & 7 & & Com 28 escravos & 2 & & - & \\
\hline Com 7 escravos & 16 & 26 & 6 & 21,5 & Com 29 escravos & - & & 1 & \\
\hline Com 8 escravos & 6 & & 3 & & Com 30 escravos & 2 & & - & \\
\hline Com 9 escravos & 3 & & 2 & & Com 31 escravos & 1 & & 1 & \\
\hline Com 10 escravos & 5 & \multirow{11}{*}{12} & - & \multirow{11}{*}{8,5} & Com 32 escravos & - & & 2 & \\
\hline Com 11 escravos & 7 & & - & & Com 33 escravos & - & & 1 & \\
\hline Com 12 escravos & 2 & & - & & Com 35 escravos & - & & 2 & \\
\hline Com 13 escravos & 1 & & 1 & & Com 36 escravos & - & & 1 & \\
\hline Com 14 escravos & 2 & & 1 & & Com 38 escravos & - & & 1 & \\
\hline Com 15 escravos & 4 & & 3 & & Com 39 escravos & - & & 1 & \\
\hline Com 16 escravos & - & & 1 & & Com 41 escravos & - & & 1 & \\
\hline Com 17 escravos & 1 & & 1 & & Com 49 escravos & 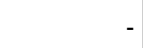 & & 1 & \\
\hline Com 18 escravos & - & & 1 & & Com 55 escravos & - & & 1 & \\
\hline Com 19 escravos & 1 & & - & & Com 77 escravos & - & & 1 & 3 \\
\hline Com 20 escravos & - & & 1 & & Com 90 escravos & - & & 1 & \\
\hline Com 21 escravos & 2 & & 1 & & Total & 192 & 100 & 94 & 100 \\
\hline
\end{tabular}

Fonte: Instituto Histórico e Geográfico do Rio Grande do Sul (1830) e White (1966, p. 123).

Em relação à quantidade de pequenos, médios e grandes senhores, também encontramos um contraste entre as duas localidades. Em Caçapava do Sul, impressionantes $82 \%$ tinham até nove escravos; a moda $(21 \%$ dos casos) foi de senhores com um cativo apenas; os médios proprietários representavam $12 \%$ do total de escravistas; somente
$6 \%$ tinham 20 ou mais escravos; e nenhum senhor foi assinalado com 50 ou mais cativos. Em Brazoria, por sua vez, a maioria dos senhores também era de pequenas posses, porém, a sua representatividade ficou em $66 \%$; a moda, da mesma forma que em Caçapava do Sul, foi de senhores com um escravo (todavia, eles perfaziam $16 \%$ dos casos, 
somente); $8,5 \%$ eram médios proprietários; o percentual de grandes senhores marca um dos contrastes entre as duas localidade estudadas - nada menos do que $22,5 \%$ deles tinham de 20 a 49 cativos; finalmente, a outra grande diferença em relação a Caçapava do Sul é que 3\% dos proprietários (exatamente 3 senhores) em Brazoria detinham mais de 50 escravos.

Por seu turno, essa peculiaridade de, em Caçapava do Sul, não haver nenhum senhor com 50 ou mais escravos deve ser devida a especificidade da fonte. Geralmente, as listas de fogos identificam todos os moradores (por consequência, todos os escravos) residentes naquele fogo. Dessa maneira, um senhor que possui outra propriedade em outro município não terá seus cativos residentes naquele segundo fogo computados no primeiro. Ou mesmo um senhor que se mudou um pouco depois de a lista ser elaborada pode ficar de fora do rol, que é um retrato daquele momento. Um exemplo da localidade de Caçapava do Sul nos ajuda a argumentar neste sentido.

Cinco anos depois da confecção da lista, em 1835, foi produzido em Caçapava do Sul o inventário do capitão Antônio Adolfo Charão. Nele consta que o miliciano tinha 58 escravos. ${ }^{8}$ Mesmo sendo uma data muito próxima à feitura da lista de fogos, o capitão Antônio Charão não aparece nesta última. Isto é, apesar de a pecuária não necessitar de tantos braços quanto as plantations de algodão, possivelmente havia senhores com uma envergadura bastante expressiva, mas que, por uma razão ou outra, não constam na lista de $1830 .^{9}$

Tabela 4 - Estrutura e concentração da posse escrava, Caçapava do Sul (1830) e Brazoria (1840)

\begin{tabular}{l|r|r|r|r|r|r|r|r}
\hline & \multicolumn{4}{|c|}{ Caçapava do Sul } & \multicolumn{4}{|c}{ Brazoria } \\
\cline { 2 - 8 } & Senhores & \multicolumn{1}{|c|}{$\%$} & \multicolumn{1}{c|}{ Escravos } & \multicolumn{1}{c}{$\%$} & Senhores & \multicolumn{1}{c}{$\%$} & Escravos & $\%$ \\
\hline De 1 a 4 escravos & 108 & 56 & 233 & 20,5 & 42 & 44,5 & 89 & 7,5 \\
De 5 a 9 escravos & 50 & 26 & 324 & 28,5 & 20 & 21,5 & 136 & 11 \\
De 10 a 19 escravos & 23 & 12 & 288 & 25,5 & 8 & 8,5 & 123 & 10 \\
De 20 a 49 escravos & 11 & 6 & 285 & 25,5 & 21 & 22,5 & 647 & 53,5 \\
Com 50 ou mais escravos & - & - & - & - & 3 & 3 & 217 & 18 \\
\hline Total & 192 & 100 & 1.130 & 100 & 94 & 100 & 1.212 & 100 \\
\hline
\end{tabular}

Fonte: Instituto Histórico e Geográfico do Rio Grande do Sul (1830) e White (1966, p. 123).

Se em Caçapava do Sul os pequenos senhores representavam mais de $80 \%$ dos proprietários, o percentual de escravos que concentravam não chegava a $60 \%$. Já os médios escravistas (com 10 a 19 cativos), que perfaziam $12 \%$ dos senhores, detinham mais escravos $(25,5 \%)$ que o dobro de sua representatividade. Finalmente, os grandes senhores, com mais de 20 escravos, concen- 
travam quatro vezes mais escravos $(25,5 \%)$ do que sua representatividade (6\%).

Em Brazoria, no entanto, se os 62 senhores com até 9 cativos representavam $66 \%$ dos proprietários, diferentemente de Caçapava do Sul, esses senhores concentravam apenas $18,5 \%$ dos escravos - ou três vezes menos sua representatividade. Já os médios escravistas, que perfaziam $8,5 \%$ dos proprietários, concentravam um percentual de escravos parecido com sua representatividade $(10 \%)$. No que diz respeito aos grandes senhores, a maior discrepância: os grandes escravistas, com 20 a 49 cativos, concentravam $(53,5 \%)$ mais que o dobro de sua representatividade $(22,5 \%)$. Somados aos três proprietários com 50 ou mais cativos, os grandes escravistas do condado texano concentravam impressionantes $61,5 \%$ dos cativos, mesmo perfazendo apenas $25,5 \%$ dos senhores neste dado reside a explicação para o alto número de escravos (13), em média, por fogo escravista na localidade.

Por fim, os números encontrados para a estrutura de posse nas duas localidades estão de acordo com os resultados averiguados para áreas de agropecuária: para a província do RS, a partir de outras fontes, como inventários post mortem e registros de batismos, e, para a República do Texas, a partir de censos do século XIX. Conforme Marcelo Matheus, a maior característica da estrutura de posse escrava nessas regiões da província (onde predominava a pecuária e a pequena agricultura) era a dispersão da posse cativa, com os pequenos senhores (até 9 escravos) concentrando boa parte dos cativos (MATHEUS, 2013). Do mesmo modo, segundo Randolph Campbell, nas décadas de 1850 e 1860, apesar de a maioria dos proprietários ser pequenos senhores, a maior parte dos escravos estava nas mãos dos médios e grandes proprietários (CAMPBELL, 1989, p. 193-194).

\section{Consideracōes finais}

A diversidade de propósitos na produção das fontes em diferentes sistemas escravistas impõe algumas dificuldades aos historiadores. Primeiramente, como é de conhecimento de todos, os documentos não foram produzidos com a finalidade de servir a pesquisas futuras. Em segundo lugar, o objetivo de cada governo e/ou autoridade em realizar levantamentos populacionais, de bens, etc., tinha em si uma intenção que dizia respeito a cada realidade específica.

Dito isso, com criatividade e ajustando as perguntas, é possível investigar alguns aspectos particulares que ajudam a iluminar um panorama mais amplo. Foi o que tentamos realizar neste estudo. Apesar de a Lista de fogos (INSTITUTO HISTÓRICO E GEOGRÁFICO DO RIO GRANDE DO SUL, 1830) de Caçapava do Sul e de The 1840 Census of Republic of Texas (WHITE, 1966) terem natureza bastante diversa, foi possível analisar alguns elementos que ora aproximavam as duas realidades, ora as afastavam.

Dentre eles, é essencial destacar a diferença dos fogos escravistas e não escravistas. Os quase $70 \%$ de fogos com escravos nos remetem a um dos aspectos salientados por Moses Finley, quando da caracterização de uma sociedade escravista: a posse escrava não está concentrada apenas nas mãos de uma elite, consequentemente, a maioria da 
população almeja se tornar um senhor de cativos (FINLEY, 1991, p. 93; BERLIN, 2006, p. 20-21). Poderíamos afirmar, também, que o trabalho escravo era a principal mão de obra, outro pressuposto elencado por Finley, embora não tenhamos tratado desta questão. ${ }^{10}$

Obviamente, aqueles 33\% de fogos com escravos em Brazoria não representavam somente a elite escravista, já que $66 \%$ dos senhores tinham até 9 cativos - embora concentrassem menos de $20 \%$ dos escravos. Pelo contrário, em Caçapava do Sul, a alta disseminação da mão de obra cativa fez com que os pequenos senhores (até 9 cativos) concentrassem praticamente $50 \%$ deles.

Por fim, parece que as atividades econômicas centrais às localidades analisadas - a pecuária em Caçapava do Sul e as plantations de algodão, principalmente, em Brazoria - foram determinantes no que diz respeito à envergadura dos grandes senhores. Embora a Lista de fogos (INSTITUTO HISTÓRICO E GEOGRÁFICO DO RIO GRANDE DO SUL, 1830) possa não ter capturado um ou outro grande escravista pelos motivos elencados, em Caçapava do Sul, nenhum senhor chegou perto dos 77 ou 90 escravos que detinham Hall Warren e Mills R., respectivamente, por exemplo (WHITE, 1966). Portanto, naquele momento em que as ondas migratórias para regiões de fronteira cresciam, do mesmo modo que as incertezas quanto ao futuro das regiões - que ainda estavam em disputa com outras nações - , a escravidão se disseminou em ambos os espaços fronteiriços, mas de maneira mais abrangente e menos concentrada no sul do Império brasileiro.
Figura 1 - Mapa do Rio Grande do Sul com Caçapava do Sul em destaque, 1831

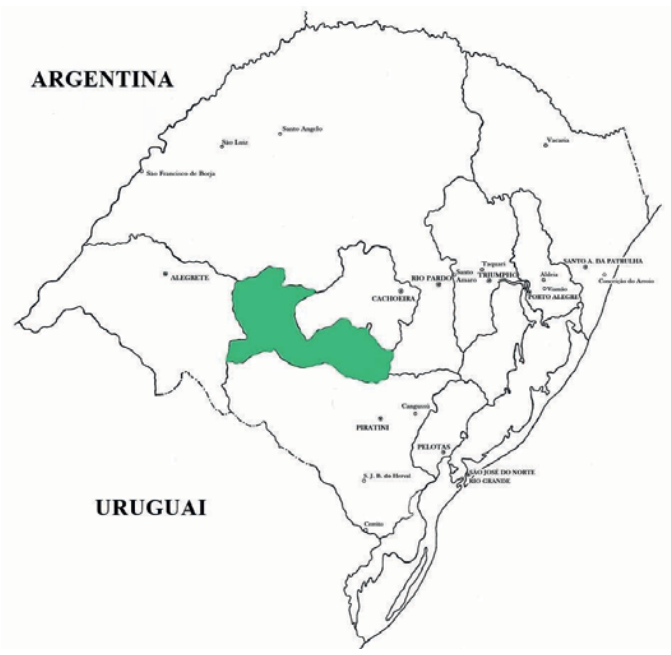

Fonte: adaptado de Felizardo (1981, p. 98).

Figura 2 - Mapa do Texas com Brazoria em destaque, 1841

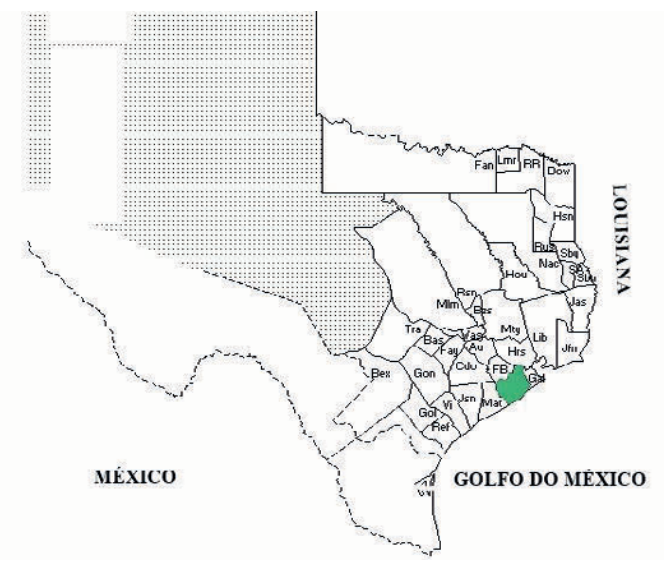

Fonte: disponível em <http://www.mapofus.org/texas/>. Acesso em: 14 dez. 2017. 


\section{Abstract}

In the 1940s, the publication of Slave and Citizen (1947), by F. Tannenbaum, opened up a new historiographical path: the comparison between the slave systems organized in the Americas. It is in this historiographical context that the present study is inserted. In it, we compare the characteristics of squad of slaves of two locations, Caçapava do Sul, in the province of Rio Grande do Sul (Brazil), and Brazoria County, in the Republic of Texas, during. Therefore, we are exploring sources as a list of homes (from 1830, for Caçapava) and a survey of property and assets (from 1840, to the US county). In advance, we can say that, although the number of homes and the amount of slaves in Caçapava do Sul and Brazoria were similar, in the first case, the slave ownership was widespread throughout the social tissue. In Brazoria, however, solely circa one third of homes were of slaveholders. Similarly, in Caçapava do Sul small and medium squad of slaves were the majority, and concentrated most of the captives, unlike Brazoria, where the trend was, in sum, large concentrated squad of slaves.

Keywords: Comparison. Ownership structure. Slavery.

\section{Resumen}

En la década de 1940, con la publicación del Slave and Citizen (1947), F. Tannenbeum abrió una nueva historiográfico: la comparación entre los sistemas esclavistas montados en las Américas. Es en este contexto historiográfico que se inserta el presente estudio. Em, se compararon las características de escravarias de dos lugares, Sur Caçapava en la provincia de Rio Grande do Sul (Brasil), y Brazoria, en la entonces República de Texas. Las fuentes utilizadas fueron una lista de fuegos (de 1830, para Caçapava) y una encuesta de la propiedad y bienes (de 1840, para al condado de Estados Unidos). De antemano, podemos decir que si bien el número de fuegos y la cantidad de esclavos en Caçapava do Sul y Brazoria sean similares, em la primera, la propiedad de esclavos fue generalizada en todo el tejido social, a la diferencia de Brazoria, donde sólo un tercio de los jefes de fuegos eran propietarios de esclavos. Se puede señalar, todavia, que, en Caçapava, han predominado las pequeñas y medianas escravarias, que concentranban la mayor parte de los cautivos, a diferencia de Brazoria, donde grandes escravarias concentradas la mayoría absoluta de los cautivos.

Palabras clave: Comparación. Esclavitud. Estructura de propriedad.

\section{Notas}

1 Conforme David Brion Davis, vinte anos depois da publicação de Slave and Citizen, ainda eram parcos "os estudos comparativos rigorosos" (DAVIS, 2001, p. 48). Devido a isso, "simplesmente não sabemos [meados da década de 1970] o suficiente sobre o tratamento efetivo dos escravos nas diferentes sociedades para permitir generalizações" (DAVIS, 2001, p. 257). Um dos estudos que podemos citar nesse sentido é: Cohen e Greene (1972).

2 Embora não seja nosso objetivo realizar um levantamento de todas as pesquisas desta natureza (nem espaço há para tanto), não poucos estudos sobre comparação entre diferentes regimes escra- 
vistas foram produzidos (DEGLER, 1976; KLEIN, 1987; GRINBERG, 2001; AZEVEDO, 2003; LIBBY; FURTADO, 2006; BEGARD, 2007; PAIVA; IVO, 2008). Mais recentemente e em acordo com a importância que os registros eclesiásticos vêm ganhando para o entendimento da história da escravidão e dos escravos na América Ibérica, há o estudo de Landers (2015).

3 Americano é utilizado, neste estudo, como sinônimo de cidadão dos EUA.

4 Há que se salientar que, em determinados momentos, após a independência da Banda Oriental (Uruguai), em 1828, muitos rio-grandenses migraram e/ou compraram propriedades no país vizinho também com o incentivo das autoridades orientais.

5 A utilização deste tipo de fonte (um levantamento de bens com a finalidade de tributação), para a realização de uma estrutura de posse, não é novidade, inclusive no Brasil (MOTTA, 1999, p. 67-108).

6 Em alguns casos, foi especificado o tratamento "Mrs." antes do nome; em outros, houve dúvida se o chefe do fogo era do sexo masculino ou feminino. Talvez o número de fogos esteja um pouco superestimado, já que, como mencionado, "pela lei, todo homem branco com mais de 21 anos, proprietário de algum bem taxável (ou seus agentes, administradores, executores e tutores), tinha que ser listados" (WHITE, 1966, p. 5, tradução nossa). Assim, mais de um indivíduo pode ter sido taxado em um mesmo fogo. Mas, caso isso tenha ocorrido, esse equívoco deve ter sido pequeno, pois, em 1850 e 1860, foram arrolados 296 e 403 fogos, respectivamente, informação disponível em: <http://mapserver.lib. virginia.edu>. Acesso em: 10 mar. 2015.

7 Este cálculo foi possível pois, no site da Igreja de Jesus Cristo dos Santos dos Últimos Dias, há tanto o censo geral da população livre, quanto o censo de escravos de cada senhor: <www.familysearch.org>. Acesso em: 03 fev. 2015.

8 Arquivo Público do Estado do Rio Grande do Sul, inventário post mortem de Antônio Adolfo Charão, autos 88, maço 4, estante 14, cartório de órfãos e ausentes, Caçapava do Sul, 1835.

9 Também em Caçapava do Sul, mas no ano de 1850, foi aberto o inventário do tenente-coronel Manoel L. da Silva Borges, que detinha 50 cativos quando da sua morte. Na Lista de fogos, o tenente-coronel tinha 24 escravos. Arquivo Público do Estado do Rio Grande do Sul, inventário post mortem do tenente-coronel Manoel Luiz da Silva Borges, autos 124, maço 4, estante 14, cartório de órfãos e ausentes, Caçapava do Sul, 1850.

10 Sobre o assunto, consultar Corrêa (2013).

\section{Referências}

ALADRÉN, Gabriel. “Sem respeitar fé nem tratados": escravidão e guerra na formação histórica da fronteira sul do Brasil (Rio Grande de São Pedro, c. 1777-1835). 2012. Tese (Doutorado em História) - Universidade Federal Fluminense, Rio de Janeiro, 2012.

AZEVEDO, Célia Marinho. Abolicionismo: Estados Unidos e Brasil, uma história comparada (século XIX). São Paulo: Annablume, 2003.

BEGARD, Laird W. The Comparative Histories of Slavery in Brazil, Cuba, and the United States. Nova York: Cambridge University Press, 2007.

BERLIN, Ira. Gerações de Cativeiro: uma história da escravidão nos Estados Unidos. Rio de Janeiro: Record, 2006.

CAMPBELL, Randolph B. An Empire for Slavery: the peculiar institution in Texas, 1821-1865. Baton Rouge: Louisiana State University, 1989.

COHEN, David W.; GREENE, Jack P. (Org.). Neither slave nor free. The freedmen of African descent in the slave societies of the New World. Baltimore: The Johns Hopkins University Press, 1972.

CORRÊA, André do Nascimento. Ao sul do Brasil oitocentista: escravidão e estrutura agrária em Caçapava, 1821-1850. 2013. Dissertação (Mestrado em História) - Programa de Pós-Graduação em História, Universidade Federal de Santa Maria, Santa Maria, 2013.

DAVIS, David Brion. O problema da escravidão na cultura ocidental. Rio de Janeiro: Civilização Brasileira, 2001.

DEBOW, J. D. B. Statistical view of the United States. New York: Norman Ross Publishing, 1990.

DEGLER, Carl. Nem Preto nem Branco: escravidão e relações raciais no Brasil e nos Estados Unidos. Rio de Janeiro: Labor do Brasil, 1976. 
FARINATTI, Luís Augusto. Confins Meridionais: famílias de elite e sociedade agrária na fronteira sul do Brasil (1825-1865). Santa Maria: Editora UFSM, 2010.

FELIZARDO, Júlia Netto. Evolução administrativa do Rio Grande do Sul. Porto Alegre: Governo do RS, 1981.

FINLEY, Moses I. Escravidão antiga e ideologia moderna. Rio de Janeiro: Graal, 1991.

FONER, Laura; GENOVESE, Eugene D. Slavery in the new world: a reader in comparative history. New Jersey: Prentice-Hall, 1969.

FUNDAÇÃO DE ECONOMIA E ESTATÍSTICA. De Província de São Pedro a Estado do Rio Grande do Sul - censos do RS 1803-1950. Porto Alegre: FEE, 1981.

GRINBERG, Keila. Alforria, Direito e Direitos no Brasil e nos Estados Unidos. Estudos Históricos, Rio de Janeiro, v. 27, n. 27, p. 63-83. 2001.

INSTITUTO HISTÓRICO E GEOGRÁFICO DO RIO GRANDE DO SUL. Lista de fogos. Caçapava, 1830. Lata 02, maço 07.

KLEIN, Herbert S. Escravidão Africana. América Latina e Caribe. São Paulo: Brasiliense, 1987.

A experiência afro-americana numa perspectiva comparativa: a situação atual do debate sobre a escravidão nas Américas. AfroÁsia, Salvador, n. 45, p. 95-121, 2012.

LANDERS, Jane et al. Researching the History of Slavery in Colombia and Brazil through Ecclesiastical and Secular Archives. In: KOMINKO, Maja. From Dust to Digital: Ten Years of the Endangered Archives Programme. Cambridge: Open Book Publishers, 2015. p. 159-192.

LIBBY, Douglas; FURTADO, Júnia (Org.). Trabalho Livre e Trabalho Escravo: Brasil e Europa, Séculos XVIII e XIX. São Paulo: Annablume, 2006.
MACGHEE, Fred Lee. The Black Crop: slavery and slave trading in nineteenth century Texas. Tese (Doutorado em História) - University of Texas, Austin, 2000.

MASSEY, Sara R. (Org.). Black Cowboys in Texas. College Station: Texas A\&M University Press, 2000.

MATHEUS, Marcelo Santos. "Dilatadas Paróquias": senhores e escravos na formação da sociedade luso-brasileira (fronteira sul de São Pedro do Rio Grande, início do século XIX). In: SIMPÓSIO NACIONAL DE HISTÓRIA, 27, Natal, 2013. Anais... Natal, 2013. p. 1-19. Disponível em: <http://www.snh2013.anpuh.org/ resources/anais/27/1371346783_ARQUIVO_ DilatadasParoquias.pdf $>$. Acesso em: 10 jun. 2017.

MOTTA, José Flávio. Corpos Escravos, Vontades Livres: posse de cativos e família escrava e Bananal (1801-1829). São Paulo: Annablume/ Fapesp, 1999.

NEAL, Tara Jane. The voice of the American slave: a quantified and humanistic study comparison of slavery in Texas and South Carolina. Tese (Doutorado em História) - Universidade do Texas, Dallas, 2001.

PAIVA, Eduardo; IVO, Isnara (Org.). Escravidão, mestiçagem e histórias comparadas. São Paulo: Annablume, 2008.

STROBEL, Abner J. The Old Plantations and Their Owners of Brazoria County. Austin: Shelby, 1980.

TANNENBAUM, Frank. Slave and Citizen: the Negro in the Americas. New York: A. A. Knopf, 1947.

WHITE, Gifford. The 1840 Census of Republic of Texas. Wilton: Pemberton Press, 1966. 